\title{
NUMERICAL ANALYSIS OF DROPLET COMBUSTION IN A CYLINDRICAL FURNACE
}

\author{
H. N. Mondal* and S. Roy \\ Department of Chemical Engineering \\ Bangladesh University of Engineering and Technology, Dhaka-1000.
}

\begin{abstract}
The combustion performance and emissions of liquid fuels are mainly influenced by the atomization of the liquid fuel, the motion and evaporation of the fuel droplets and mixing of fuel and air. A reliable description and simulation of spray combustion requires a detailed understanding of droplet ignition and combustion. Recently, it has become apparent that an understanding of the mechanisms related to spray combustion is the key to the development of non-polluting and high performance devices. In this study liquid droplets of Toluene is taken into consideration and their burning characteristics are investigated for different combustor geometries and droplet sizes. Non-adiabatic presumed probability density function $(P P D F)$ model is used with high Reynolds number $k-\varepsilon$ model. Droplet breakups are handled with ReitzDiwakar model. Preliminary investigation shows that droplet size, inlet pattern and oxidizer temperature have profound effect on combustion temperature distribution and pollutant formation.
\end{abstract}

\section{Introduction}

In many technical systems sprays of small fuel droplets are burnt in the presence of air. The liquid fuel used as the energy source is atomized into smaller droplets in order to increase the surface area of fuel exposed to the hot gases and to facilitate rapid gasification and mixing with the oxygen rich ambience. Droplet burning has relevance to many practical combustion devices, including diesel, liquid rocket engine, and gas turbine engines, as well as oil fired boilers, furnaces, and process heaters. The liquid fuel is injected into the combustion chamber and the combustion occurs as the droplets vaporize and fuel vapor mixes with air. Hence spray dynamics and combustion studies are extremely important to determine flame stability behavior at widely varying loads, to ensure safety and efficient utilization of energy, as well as to better understand the mechanisms of pollutants formation and destruction. Numerical simulation of these processes is a very challenging task due to the stiffness of the chemistry and the coupling with the flow. Moreover, as the fuel is injected at high velocities, the flow nature is turbulent in the spray vicinity and therefore the turbulence-chemistry interactions need to be accounted for. A reliable description and simulation of spray combustion requires a detailed understanding of droplet ignition and combustion. Recently, it has become apparent that an understanding of the mechanisms related to spray combustion is the key to the development of nonpolluting and high performance devices. An important approach is to use advanced computer models for such fundamental studies and for developing practical devices. The development of advanced computers with high speed processors enables theoreticians to formulate and numerically solve comprehensive models with more detailed consideration of physical and chemical processes involved in spray combustion.

The combustion of a single liquid droplet in a quiescent atmosphere has been studied extensively both experimentally and numerically. Most of the experimental researches deal with the fuel ethanol ${ }^{1,2,3}$,

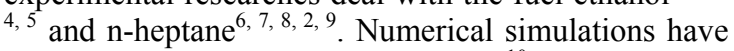
been presented for methanol droplets ${ }^{10}$ and n-heptane droplets $^{11,12,13,14}$. Only a little number of studies do not assume spherical symmetry and nevertheless consider the physics of the droplets and the chemical processes in detail. In this study, burning characteristics of toluene droplets in a cylindrical furnace is taken into consideration. Effect of different droplet sizes, different number of droplet parcels, different flow rates of primary and secondary air are investigated. Full three dimensional geometry without any cylindrical or periodic symmetry is taken as the computational domain.

\section{Governing Equations}

Droplet evaporation and subsequent combustion is modeled as dispersed multiphase flow consisting of a continuous phase, which may be gaseous or liquid, and one dispersed phase in the form of liquid droplets. In general, the motion of the dispersed phase will be 
influenced by that of the continuous phase and vice versa. Here the dispersed phase is volatile, reactive, heat and mass transfer occurs between the phases. The conservation equation for droplets in the Lagrangian framework are as follows:

The momentum equation for a droplet of mass $m_{\mathrm{d}}$ is

$m_{d} \frac{d \vec{u}_{d}}{d t}=\vec{F}_{d r}+\vec{F}_{p}+\vec{F}_{a m}+\vec{F}_{b}$

where

$\vec{u}$ is fluid velocity, $\vec{u}_{d}$ is droplet velocity, $\vec{F}_{d r}$ is drug force, $\vec{F}_{p}$ is pressure force, $\vec{F}_{a m}$ is virtual mass force, and $\vec{F}_{b}$ is the body force. In the presence of mass transfer, the droplet mass rate of change is given by

$\frac{d m_{d}}{d t}=-A_{s} K_{g} p_{t} \ln \frac{\left(p_{t}-p_{v, \infty}\right)}{\left(p_{t}-p_{v, s}\right)}$

where $A_{\mathrm{s}}$ is the droplet surface area, $K_{\mathrm{g}}$ is the mass transfer coefficient, and pt, $p_{v, \infty}$ and $p_{v, \infty}$ are the gas pressure and partial pressures of the vapor in the droplet surroundings and its surface, respectively.

The droplet energy balance takes into account the mechanisms of surface heat transfer rates $q_{\mathrm{d}}$ per unit surface area and loss/gain due to phase change, thus:

$m_{d} \frac{d\left(c_{p, d} T_{d}\right)}{d t}=-A_{s} q_{d}+h_{f g} \frac{d m_{d}}{d t}$

where $c_{\mathrm{p}, \mathrm{d}}$ the droplet specific heat and $h_{\mathrm{fg}}$ the latent heat of phase change.

Droplets may become unstable under the action of the interfacial forces induced by their motion relative to the continuous phase. For the break-up of liquid droplets in a gaseous stream a set of widely used models exist. Some of them are Reitz and Diwakar, Pilch and Erdman, Hsiang and Faeth etc. In this work Reitz and Diwakar is used which is briefly described below.

\section{Reitz and Diwakar model}

According to this model ${ }^{15,16}$, droplet break-up due to aerodynamic forces occurs in one of the following modes:

- 'Bag break-up', in which the non-uniform pressure field around the droplet causes it to expand in the low-pressure wake region and eventually disintegrate when surface tension forces are overcome.

- 'Stripping break-up', a process in which liquid is sheared or stripped from the droplet surface

In each case, theoretical studies have provided a criterion for the onset of break-up and concurrently an estimate of the stable droplet diameter, $D_{d}$ stable , and the characteristic time scale $\tau_{\mathrm{b}}$ of the break-up process. This allows the break-up rate to be calculated from

$\frac{d D}{d t}=\frac{\left(D_{d}-D_{d, \text { stable }}\right)}{\tau_{b}}$

where $D_{d}$ is the instantaneous droplet diameter. The criteria and time scales are as follows:

Bag break-up:

Here, instability is determined by a critical value of the Weber number, We, thus:

$W e \equiv \frac{\rho\left|\vec{u}-\vec{u}_{d}\right|}{2 \sigma_{d}} \geq C_{b 1}$

where $\sigma_{\mathrm{d}}$ is the surface tension coefficient, and $\mathrm{C}_{\mathrm{b} 1}$ is an empirical coefficient having a value in the range 3.6 to 8.4. ${ }^{12}$ STAR-CD uses $\mathrm{C}_{\mathrm{bl}}=6$ as the default setting. The stable droplet size is that which satisfies the equality in the above equation. The associated characteristic time is

$\tau_{b}=\frac{C_{b 2} \rho_{d}^{1 / 2} D_{d}^{3 / 2}}{4 \sigma_{d}^{1 / 2}}$

in which $C_{b 2} \approx \pi$.

Stripping break-up:

The criterion for the onset of this regime is

$\frac{W e}{\sqrt{\mathrm{Re}_{d}}} \geq C_{s 1}$

where $\mathrm{Re}_{\mathrm{d}}$ is the droplet Reynolds number and $\mathrm{C}_{\mathrm{s} 1}$ is a coefficient with the value $0.5 .^{15}$ The characteristic time scale for this regime is

$\tau_{b}=\frac{C_{s 2}}{2}\left(\frac{\rho_{d}}{\rho}\right)^{1 / 2} \frac{D_{d}}{\left|\vec{u}-\vec{u}_{d}\right|}$ 
Here, the empirical coefficient $\mathrm{C}_{\mathrm{s} 2}$ is in the range 2 to $20{ }^{15}$ The default setting in STAR-CD for $\mathrm{C}_{\mathrm{s} 2}$ is 20 .

The continuous phase conservation equations are essentially the k- $\varepsilon$ model of the time averaged NavierStokes equations, species transport and energy transport equations.

\section{PPDF with enthalpy transport}

In this model, the following transport equation is solved for enthalpy:

$$
\begin{gathered}
\frac{1}{\sqrt{g}} \frac{\partial}{\partial t}(\sqrt{g} \rho h)+\frac{\partial}{\partial x_{j}}\left(\rho \tilde{u}_{j} h-F_{h, j}\right)=\frac{1}{\sqrt{g}} \frac{\partial}{\partial t}(\sqrt{g} p) \\
+\frac{\partial}{\partial x_{j}}\left(\tilde{u}_{j} p\right)-p \frac{\partial u_{j}}{\partial x_{j}}+\tau_{i j} \frac{\partial u_{i}}{\partial x_{j}}+s
\end{gathered}
$$

where $\mathrm{h}$ is the static enthalpy. The time average value of temperature, density and species concentrations are obtained using the following equation:

$\phi=\int_{0}^{1} \hat{\phi}(f) P(f) d f$

where $\hat{\phi}$ is any variable which can be uniquely related to the mixture fraction, $f$. The equation for the mixture fraction is of the standard form, whereas the transport equation for its variance $g_{f}$ is given below ${ }^{17}$ :

$$
\begin{gathered}
\frac{1}{\sqrt{g}} \frac{\partial}{\partial t}\left(\sqrt{g} \rho g_{f}\right)+\frac{\partial}{\partial x_{j}} \rho \tilde{u}_{j} g_{f}=\frac{2 \mu_{t}}{\sigma_{g}}\left(\frac{\partial \mathrm{f}}{\partial x_{j}}\right)^{2} \\
\frac{\partial}{\partial x_{j}}\left(\rho D_{g}+\frac{\mu_{t}}{\sigma_{g}}\right) \frac{\partial g_{f}}{\partial x_{j}}-\mathrm{C}_{\mathrm{D}} \rho \frac{\varepsilon}{\kappa} \mathrm{g}_{\mathrm{j}}
\end{gathered}
$$

The presumed pdf form, $P(f)$, is a $\beta$ function $^{10}$

$$
p(f)=\frac{f^{a-1}(1-f)^{b-1}}{\int_{0}^{1} f^{a-1}(1-f)^{b-1} d f}
$$

in which

$$
\begin{aligned}
& a \equiv \frac{f}{g_{f}}\left[f(1-f)-g_{f}\right] \\
& b=\frac{(1-f)}{f} a
\end{aligned}
$$

The temperature is obtained from the mass fractions and transported enthalpy. It is also assumed that the density is related to pressure, temperature and chemical species via the ideal gas law.

\section{Description of the unit}

The basic geometry is shown in Fig. 1. Primary air inlet consists of two concentric layers of holes with a total surface are of $0.0141 \mathrm{~m}^{2}$. There are three secondary air inlets with surface areas. The areas of secondary air inlet 1,2 and 3 are $0.012,0.009$ and $0.009 \mathrm{~m}^{2}$ respectively. The outlet has a surface area of $0.08 \mathrm{~m}^{2}$. Input parameters are velocity, number and parcels of droplets, and primary and secondary air velocities.

\section{Result and Discussion}

Different droplet sizes, number of parcels, droplet numbers in each parcel and effect of secondary air variation are investigated by numerical simulation. Fig. 2 and Fig. 3 show the droplet generation and subsequent evaporation as it carried up by the swirled primary air from the bottom of the cylindrical furnace.

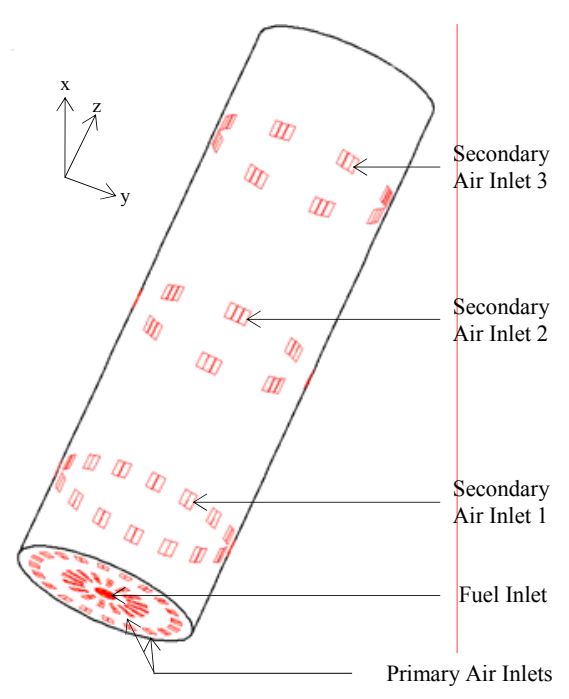

Fig. 1. Geometry of the model considered. Volume of the cylinder is $0.0964 \mathrm{~m}^{3}$. Total area of primary air inlet is $0.0141 \mathrm{~m}^{2}$. The areas of secondary air inlet 1,2 and 3 are $0.012,0.009$ and $0.009 \mathrm{~m}^{2}$ respectively.

The injected droplet diameter of Fig. 3 is 1.6 times the injected droplet diameter of Fig. 2 and as a result Fig. 3 shows that droplets with bigger diameters take longer time to vaporize completely and hence travels longer path along the furnace. 


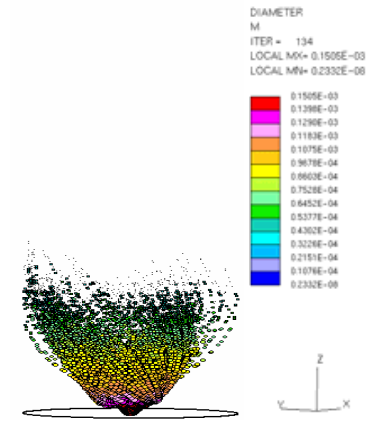

Fig 2. Droplet generation and evaporation for droplet diameter of $0.15 \mathrm{~mm}$ with 360 parcels with each parcels contains 70,000 droplets.

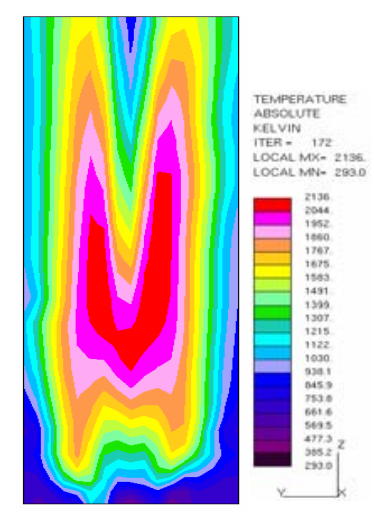

Fig 4. Droplet generation and evaporation for droplet diameter of $0.15 \mathrm{~mm}$ with 180 parcels with each parcels contains 70,000 droplets.

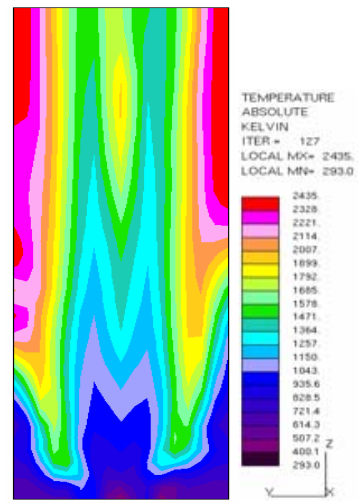

Fig 6. Temperature distribution diameter of 0.25 mm with 360 parcels with each parcels contains 35,000 droplets.

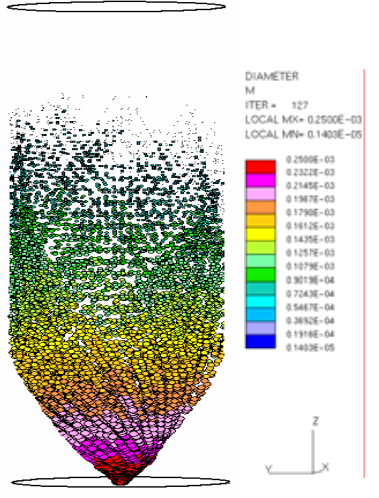

Fig 3. Droplet generation and evaporation for droplet diameter of $0.25 \mathrm{~mm}$ with 180 parcels with each parcels contains 35,000 droplets.

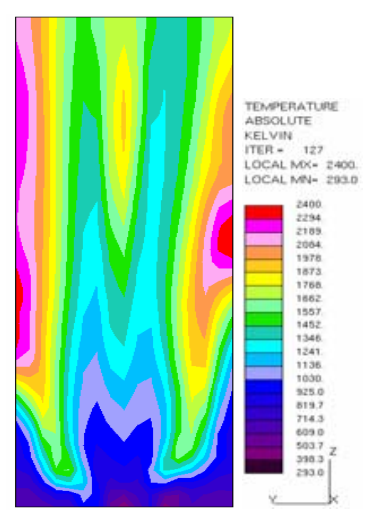

Fig 5. Droplet generation and evaporation for droplet diameter of $0.25 \mathrm{~mm}$ with 180 parcels with each parcels contains 70,000 droplets.

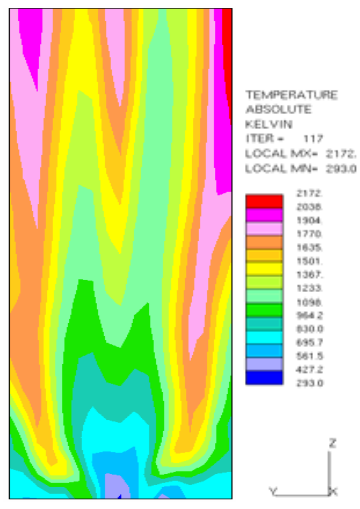

Fig 7. Temperature distribution diameter of $0.15 \mathrm{~mm}$ with 180 parcels with each parcels contains 70,000 droplets. (Reduced Secondary Air) 
Fig. 4 and Fig. 5 compare the resulting absolute temperature distribution for different droplet diameters. In Fig. 4, due to smaller diameter, the droplets vaporize quickly so the maximum temperature occurs near the bottom of the furnace. Whereas in Fig. 5, complete vaporization of the bigger diameter droplets takes longer time and as a result higher temperature occurs near the top of the furnace.

Fig. 5 shows the effect of the number of droplet parcels compared to Fig. 3 and Fig. 4. Fig. 6 shows the effect of reduced secondary air on the temperature distribution of the furnace. It becomes clear that no secondary air at all or reduced secondary air helps to spread the flame near the wall of the furnace which is not desirable due to the requirement of high temperature resistance materials.

\section{Conclusions}

In this study burning characteristics of liquid Toluene droplets are investigated for different combustor geometries and droplet sizes. Droplet breakups are handled with Reitz-Diwakar break-up model. Combustion calculations and turbulence modeling are handled using non-adiabatic presumed probability density function (PPDF) model and high Reynolds number $\mathrm{k}-\varepsilon$ model respectively. Investigation showed that droplet size, inlet pattern and oxidizer temperature have profound effect on combustion temperature distribution and pollutant formation.

\section{References}

1. Marchese, A. J., Dryer, F. L., Vedha-Nayagam, M., and Colantonio, R., "Microgravity Combustion of Methanol and Methanol/Water Droplets: Drop Tower Experiments and Numerical Modeling", Twenty-Sixth International Symposium on Combustion, Pittsburgh, PA, p. 1209, 1996.

2. Vieille, B., Chauveau, C., Chesneau, X., Adide, A., and Gökalp, I., " High-Pressure Droplet Burning Experiments in Microgravity", Twenty-Sixth Symp. (Inter.) on Comb. 1, The Comb. Inst., Pittsburgh, pp. 1259-1266, 1996

3. Okai, K., Moriue, O., Araki, M., Tsue, M., Kono, M., Sato, J., Dietrich. D. L. and Williams, F. A., "Combustion of Single Droplets and Droplet Pairs in a Vibrating Field Under Microgravity", Proceedings of the Combustion Institute, 28, pp. 977-983, 2000.

4. Chauveau, C., Vieille, B., Gökalp, I., Segawa, D., Kadota, T., And Nakainkyo, "A. Effects of gravitational acceleration on high pressure combustion of methanol droplets", Journal de Chimie Physique, 96, 1031-1037, 1999.

5. Shaw, B.W, H. A. Dwyer and J. B. Wei, "Studies on Combustion of Single and Double Streams of Methanol and Methanol/Dodecanol Droplets", Combustion Science and Technology, ,174: pp. 29-50, 2002.

6. Faeth, G.M., and Olson, D.R., SAE Transactions, pages 1793-1802, 1968.

7. Hara, $H$. and Kumagai, S. Proc. Combust. Inst. 23 (1991) 1605-1 61 0, Pittsburgh, USA.

8. Jackson, G.S., and Avedisian, C.T., Proceedings of the Royal Society of London A. Mathematical, Physical and Engineering Sciences, 446:255-276, 1994.

9. Nayagam, V., Haggard, J.B., Colantonio, R.O., Marchese, A.J., Dryer, F.L., Zhang, B.L., and Williams, F.A., AIAA Journal, 36:1369-1378, 1998.

10. Cho, S.Y., Choi, M.Y., and Dryer, F.L., In Twenty-Third Symposium (International) on Combustion, The Combustion Institute, pages 1611-1617, Pittsburgh, 1990.

11. Cho, S. Y., and Dryer, F. L., Combustion Theory and Modelling, 3:267-280, 1999.

12. Marchese, A. J., Dryer, F. L., and Nayagam, V., 1999, Combustion and Flame, 116:432-459, 1999.

13. Schnaubelt, S., Moriue, O., Eigenbrod C., and Rath, H. J., Microgravity Science Technology, XIII/1:20-23, 2001.

14. Moriue, O., Mikami, M., Kojima, N. and Eigenbrod, C., "Numerical Simulations of the Ignition of n-Heptane Droplets in the Transition Diameter Range from Heterogeneous to Homogeneous Ignition", Proceedings of the Combustion Institute, 30, pp. 1973-1980, 2005.

15. Nicholls, J.A. 'Stream and droplet breakup by shock waves', NASA SP-194 (Eds. D.T. Harrje and F.H. Reardon), pp. 126-128, 1972.

16. Reitz, R.D., and Diwakar, R. 'Effect of drop breakup on fuel sprays', SAE Technical Paper Series, 860469, 1986.

17. Methodology Manual, STAR-CD Version 3.15, Computational Dynamics Ltd, 2001. 